\title{
Ecology of amorphous aggregations (marine snow) in the Northern Adriatic Sea. V. Role of fecal pellets in marine snow
}

\author{
Alexander B. Bochdansky*, Gerhard J. Herndl** \\ Dept of Marine Biology, Inst. of Zoology, University of Vienna, Althanstrafie 14, A-1090 Vienna, Austria
}

\begin{abstract}
Abundance and size classes of fecal pellets in marine snow as compared to the ambient water were investigated in the Northern Adriatic Sea during summer 1990 and 1991. Numbers of fecal pellets in marine snow varied with depth and kind of aggregates ranging from 31 to 353000 fecal pellets $l^{-1}$ marine snow. Fecal pellets were found to be enriched in marine snow by a factor ranging from 0.3 to 3800 . Small fecal pellets $\left(<10^{5} \mu^{3}{ }^{3}\right)$ contributed up to $68 \%$ of the total fecal pellet volume in marine snow. Fecal pellets are a major source of carbon in marine snow (up to $37 \%$ ) and they are effectively scavenged especially by large $(>1 \mathrm{~m})$ amorphous aggregates. Besides low sinking velocities, resuspension and reingestion, trapping of fecal pellets by marine snow is an efficient mechanism to keep fecal pellet-derived carbon confined to the upper layers of stratified water columns.
\end{abstract}

Fecal pellets produced by zooplankton are known to be a major vehicle for vertical transport of particulate organic carbon (POC) in the open ocean (Pilskaln \& Honjo 1987). Rapidly sinking fecal pellets contribute to the pelagic-benthic carbon flux (Emerson \& Roff 1987) since large fecal pellets display high sinking rates and therefore settle out of the euphotic zone without being significantly decomposed (Small et al. 1979. Suess 1980). On the other hand there is evidence for biodegradation, coprophagy, resuspension and mechanical breakage which increase the residence time of fecal pellet derived POC in a given depth stratum of the water column (Honjo \& Roman 1978, Paffenhöfer \& Knowles 1979, Bathmann et al. 1987, Emerson \& Roff 1987. Lampitt et al. 1990). Turbulence in the mixed layers and the development of pycnoclines in stratified waters can also account for a prolonged residence time of even large fecal pellets (Alldredge et al. 1987). Besides fecal pellets, marine snow is the major component of particulate organic fluxes in the ocean (All-

\footnotetext{
- Present address: Ocean Sciences Centre, Memorial University, St. Johns, Newfoundland, Canada A.1C 5 S7

- Addressee for reprint requests
}

dredge \& Silver 1988). Urrère \& Knauer (1981) found that numerous small items (including fecal pellets) are associated with large amounts of flocculent material found in sediment traps in the northeast Pacific; often fecal pellets and marine snow flux cannot be treated separately since essentially all the material entering sediment traps arrive in association with marine snow (Asper 1987). In eutrophic marine ecosystems a large fraction of the primary production remains ungrazed and contributes to rapid POM fluxes to the bottom (Smetacek 1985, Lochte \& Turley 1988) or provokes the formation of large buoyant mucous sheets (Stachowitsch et al. 1990. Herndl et al. in press) which does not necessarily lead to enhanced vertical transport (Puskaric et al. 1992).

In this study we investigated the contribution of fecal pellets to the formation of marine snow and discuss their role in particle flux dynamics in a shallow, neritic environment based on recent findings on the characteristics of large mucoid aggregates in the Northern Adriatic Sea.

Methods. The sampling locations were 1 to $3 \mathrm{~km}$ off the Laboratorio di Biologia Marina at Aurisina-Trieste (Italy) and $3 \mathrm{~km}$ off Rovinj (Croatia) in the Northern Adriatic Sea. Sampling was performed during summer 1990 and 1991. Mesozooplankton was collected by double-oblique net hauls between $10 \mathrm{~m}$ depth and the surface with a $300 \mu \mathrm{m}$ plankton net equipped with a flowmeter. Marine snow and ambient water containing no visible aggregates were collected by SCUBA diving with $60 \mathrm{ml}$ disposable and $0.8 \mathrm{l}$ plexiglass syringes, respectively. Marine snow was sampled without inclusion of ambient water, thus the syringe volume of $60 \mathrm{ml}$ is also the actual volume of marine snow sampled including porewater. Samples were either examined immediately after collecting or stored in $4 \%$ buffered formalin-seawater solutions. To estimate the flux of fecal pellets to the bottom, 4 sediment traps $(63 \mathrm{~mm}$ 
inner diameter; height: width ratio $=6.5: 1$ ) were deployed in $27 \mathrm{~m}$ ca $0.5 \mathrm{~m}$ above the bottom and exposed for 24 h on 3 and 5 September 1991, respectively. During the deployment of the sediment traps calm weather conditions led to reduced turbulence regimes in the water column; therefore resuspension of the sediment is expected to be negligible.

Fecal pellets were counted and measured under a dissecting microscope (magnification: $\times 90$ ) in both marine snow and ambient water. Their volume was calculated by measuring length and diameter in order to calculate their volume assuming a cylindrical shape. The highly structured matrix of marine snow made it extremely difficult to detect fecal pellets smaller than those enumerated during this study. Oval-shaped fecal pellets were generally rare; since they are also hardly distinguishable from decay stages of certain algae like peridineans which are common in marine snow, we restricted counting and sizing to intact cylindrical fecal pellets known from fecal pellet production experiments with mixed zooplankton samples. For total organic carbon (TOC) analysis, 60 to $300 \mathrm{fecal}$ pellets were collected by plexiglass tubes on which nets (mesh size $200 \mu \mathrm{m})$ were fixed at the lower end (Fig. 1). After removing excess seawater with a pipette they were rinsed twice with redistilled water, suspended in $1 \mathrm{ml}$ of redistilled water and stored frozen at $-20^{\circ} \mathrm{C}$ in precombusted $\left(480^{\circ} \mathrm{C}\right.$ for $4 \mathrm{~h}$ ) and sealed ampoules until analyses. The fecal pellets were hydrolyzed with $1 \mathrm{ml}$ of $12 \mathrm{~N} \mathrm{HCl}$ for $24 \mathrm{~h}$ at $110^{\circ} \mathrm{C}$, then evaporated to dryness and re-dissolved in $2 \mathrm{ml}$ double-distilled water. Two ml of marine snow and clouds (for terminology see Stachowitsch et al. 1990) were collected with syringes centrifuged and resuspended in $5 \mathrm{ml}$ redistilled water to remove the salt. This procedure was repeated twice Subsequently the samples were ultrasonicated to

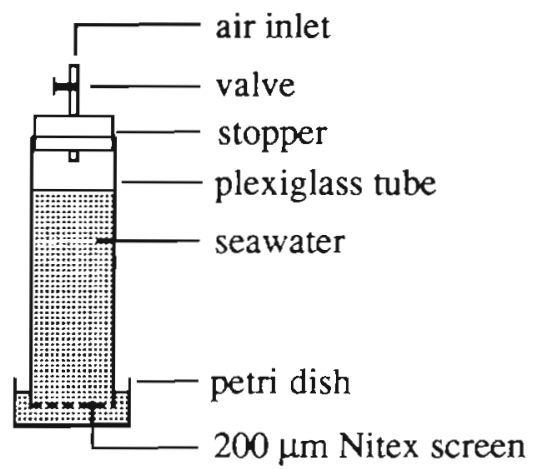

Fig. 1 Device to collect fecal pellets. Length of the tube is $40 \mathrm{~cm}$ ( $5 \mathrm{~cm}$ inner diameter). The water column containing zooplankton organisms is held within the tube by a stopper on the top of the tube and the surface tension of the water at the Nitex screen. Petri dishes can easily be removed without losing water. A new petri dish is filled by letting air through the valve thereby washing fecal pellets into the petri dish obtain a homogeneous suspension in redistilled water. The organic carbon contents of fecal pellets and marine snow samples were determined by a Beckmann TOCmaster $915-\mathrm{B}$ after acidifying the samples with $50 \mu \mathrm{l}$ of $2 \% \mathrm{HCl}$ and purging for 10 min with $\mathrm{CO}_{2}$-free air. The instrument was calibrated using maltose as standard.

A mixed zooplankton sample $(>300 \mu \mathrm{m})$ from September 1991 mainly consisting of Penilia avirostris was divided into 6 equal parts by a plankton splitter and then placed into 6 'net-bottomed' tubes each containing about 800 individuals (Fig. 1). These tubes were filled with freshly collected seawater from the surface layer. In $30 \mathrm{~min}$ intervals these tubes were sampled with petri dishes by opening the valve at the upper end (Fig. 1) and filling 3 petri dishes at each step over a period of $3 \mathrm{~h}$. The last of the 3 subsamples contained less than $5 \%$ of the total fecal pellets collected at each sampling indicating that 3 subsamples were sufficient to remove nearly all of the settled fecal pellets. Thereafter the fecal pellets were counted and their number divided by the number of zooplankton present in each tube.

To measure the stickiness of the surface of fecal pellets we constructed a rectangular flow channel (width $2 \mathrm{~mm}$, height $1 \mathrm{~mm}$, upper side open) made out of glass. This flow channel was placed in a petri dish and the petri dish was filled with raw seawater. Then a tube described in Fig. 1 was filled with raw seawater containing a mixed zooplankton sample in September (ca 100 ind. $1^{-1}$, freshly caught by net-hauls). The tube was brought in an upright position into contact with the flow channel. After $2 \mathrm{~h}$, a sufficient amount of fecal pellets had settled through the net into the flow channel. The tube was lifted and the upper side of the flow channel carefully closed by placing a microscope slide on the top of the flow channel. This procedure enabled us to collect fecal pellets with a minimum of disturbance and allowed the fecal pellets to settle right onto the experimental device. The flow of water was increased stepwise by opening the valve connected by a tube with a reservoir and the flow channel; by regulating the flow of the water a maximum velocity of $110 \mathrm{~mm} \mathrm{~s}^{-1}$ was obtained. The water level in the reservoir was held constant to apply a constant hydrostatic pressure. The velocity was calculated by measuring the volume flowing through the flow channel per unit time. The fecal pellets which remained in the flow channel were counted at each step under a dissecting microscope. Glass beads ( 1 to 50 um in diam.) were exposed to the same current velocities as the fecal pellets and served as controls.

Net-bottomed tubes (Fig. 1) were also used to separate freshly egested fecal pellets from a mixed zooplankton sample (>300 $\mu \mathrm{m}$ ) in September 1991. About 200 large copepod fecal pellets (length ca $200 \mu \mathrm{m}$, 
Table 1. Fecal pellet abundance in marine snow $<5 \mathrm{~cm}$ in size (stringers) and clouds $>1 \mathrm{~m}$ as compared to the ambient water expressed as no. of fecal pellets $1^{-1}$ Numbers are based on collections with syringes $(0.81$ for ambient water, $60 \mathrm{ml}$ for marine snow) by SCUBA diving. No. of replicates given in parentheses. nd: not determined

\begin{tabular}{|c|c|c|c|}
\hline Date & Ambient water & Marine snow (stringers) & Clouds \\
\hline 26 Jul 1990 & nd & $9880(1)$ & nd \\
\hline 5 Jun 1991 & $174(3)$ & $1200(8)$ & nd \\
\hline 3 Jul 1991 & $240(1)$ & $46600(5)$ & nd \\
\hline 4 Jul 1991 & nd & $37650(5)$ & nd \\
\hline 6 Jul 1991 & $167(2)$ & $56333(8)$ & nd \\
\hline 9 Jul 1991 & $57(2)$ & $49240(5)$ & nd \\
\hline 10 Jul 1991 & $23(1)$ & $82600(1)$ & nd \\
\hline 12 Jul 1991 & $80(1)$ & $123200(1)$ & $272400(5)$ \\
\hline 11 Aug 1991 & nd & nd & $37667(6)$ \\
\hline 27 Aug 1991 & $222(6)$ & nd & $327(6)$ \\
\hline 28 Aug 1991 & $122(6)$ & $59810(8)$ & $31-1078$ \\
\hline 29 Aug 1991 & nd & $18523(2)$ & $266-353234(4)$ \\
\hline
\end{tabular}

width ca $40 \mu \mathrm{m})$ in each petri dish were incubated in raw seawater at dim light at $25^{\circ} \mathrm{C}$ (which is roughly the temperature of the surface water layer in the Northern Adriatic Sea during summer) without any disturbance to simulate fecal pellet decomposition attached to a surface. At time 0 and $24,48,72 \mathrm{~h}$ and $5 \mathrm{~d}$ after starting the incubation, ca 20 fecal pellets were collected with a pipette, stained with acridine orange (Jacobsen \& Azam 1984) and carefully transferred onto black Nuclepore filters $(0.2 \mu \mathrm{m}, 25 \mathrm{~mm}$ diameter), examined and sized under the epifluorescence microscope. Only fecal pellets with at least partly intact membranes were considered. In order to test whether or not chitin is a main structural compound of the fecal pellet membranes, experiments with chitinase were performed. Large copepod fecal pellets (see Table 2) were put onto several depression slides in a drop of a chitinase-seawater solution (1 unit Chitinase, Sigma Chemical, in $10 \mathrm{ml}$ of

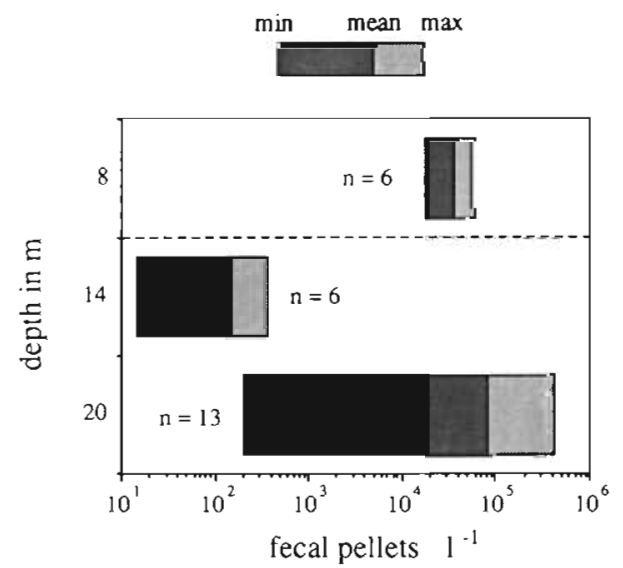

Fig. 2. No. of zooplankton fecal pellets $l^{-1}$ of marine snow in the stratified water column in late August 1991 Dashed line indicates the position of a strong pycnocline. The wide range over more than 3 orders of magnitude indicates a high variability of fecal pellet abundance with depth and within 1 depth layer depending on the type of aggregate
$0.2 \mu \mathrm{m}$ filtered seawater). Fecal pellets placed in $0.2 \mu \mathrm{m}$ filtered seawater containing no chitinase solution served as controls. After $6 \mathrm{~h}$ at $25^{\circ} \mathrm{C}$, the fecal pellets were disturbed with a fine needle under a dissecting microscope in order to qualitatively examine the integrity of the fecal pellets.

Results. The most dominant mesozooplankton species in June were Acartia clausi (more than $50 \%$ of the total numbers of zooplankton), Evadne sp. and Podon sp. (together $30 \%$ ), and calanoid copepods belonging to the Paracalanidae and Centropagidae. From July throughout August and early September Penilia avirostris dominated over all other mesozooplankton species (68 to $74 \%$ ). In early September $90 \%$ of the mesozooplankton were cladocerans (Penilia avirostris, Evadne sp. and Podon sp.). Total mesozooplankton numbers in the surface waters were similar at all sampling periods ranging from 10 to 14 ind. $1^{-1}$ from June to September 1991. Fecal pellet abundance in ambient water remained in the same order of magnitude during all months, whereas fecal pellet abundance in marine snow varied over 5 orders of magnitude (Table 1). In June 1991, fecal pellets in marine snow were less abundant than in July 1990 and 1991. respectively, and in late August 1991. Enrichment factors (EF's, no. of fecal pellets in marine snow/number of fecal pellets in ambient water) were low in June 1991 $(E F=6.9)$, and increased steadily in stringers (for terminology of marine snow see Stachowitsch et al. 1990; $\mathrm{EF}=33.8$ to 1540 ) in July 1991. Highest EF's were obtained for clouds ( $E F=3405)$. In late August 1991, EF's ranged from 0.3 up to 3800 (Table 1) depending on the depth (Fig. 2). The abundance of fecal pellets was significantly lower in marine snow beyond a strong pycnocline $(14 \mathrm{~m})$ compared to the abundance at 8 and $20 \mathrm{~m}$ (Mann Whitney, $\mathrm{p}=0.01$, Fig. 2) In general, small fecal pellets $\left(<10^{5} \mu \mathrm{m}^{3}\right)$ made up a large portion of the total fecal pellet volume in 

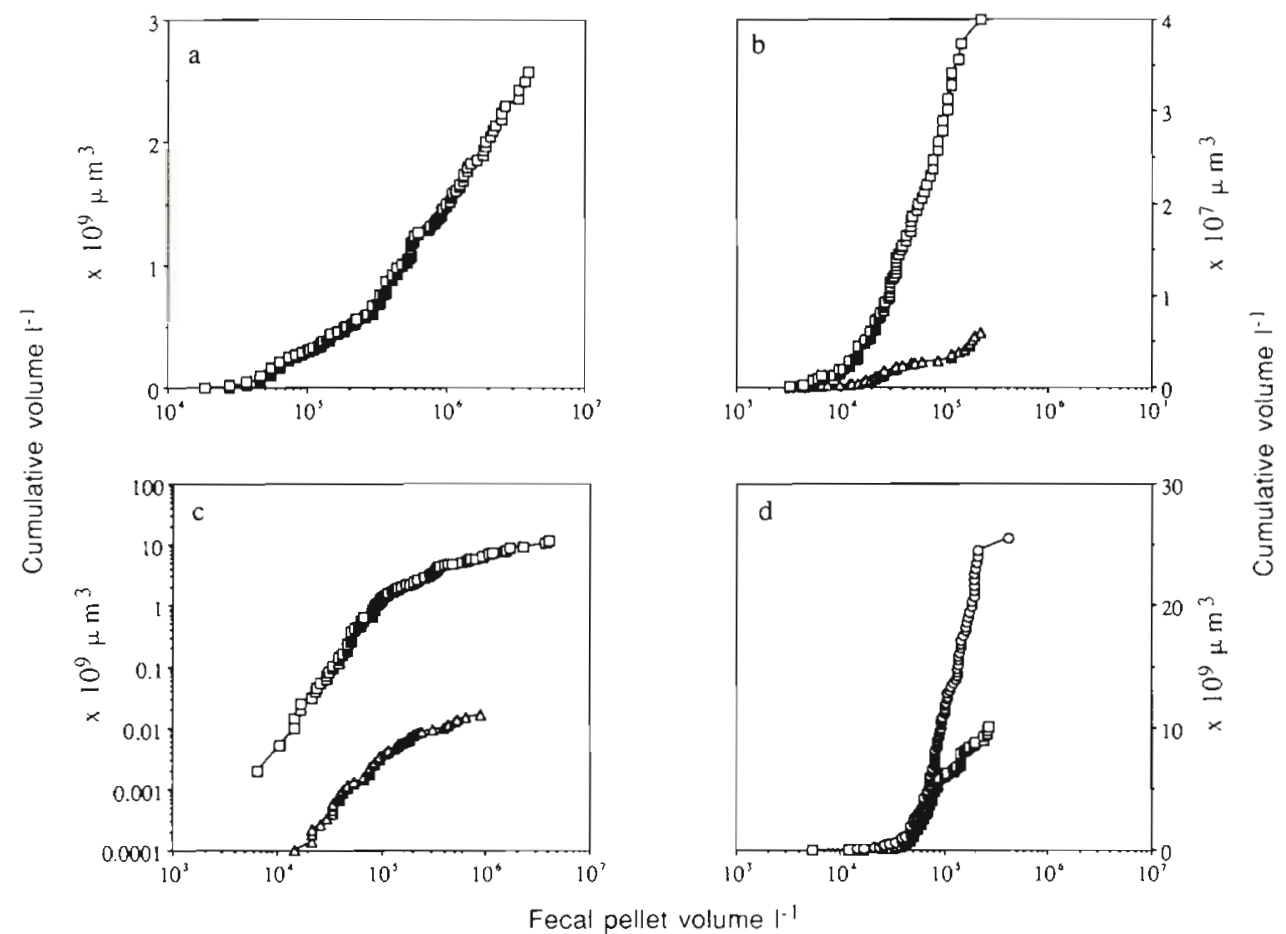

Fig. 3. Cumulative distribution of fecal pellets $\left(n=\right.$ ca $\left.10000 \mathrm{I}^{-1}\right)$ of various sizes to the total volume of fecal pellets in $1 \mathrm{l}(\theta)$ marine snow, (') ambient water and (o) clouds in (a) July 1990, (b) June 1991, (c) 3 \& 4 July 1991 and (d) 12 July 1991. (a) Fecal pellets up to $1 \times 10^{5} \mu \mathrm{m}^{3}$ contribute to $12 \%$ of the total fecal pellet-volume of about $2.6 \times 10^{9} \mu^{3} \mathrm{l}^{-1}$ (marine snow). (b) Total volume of fecal pellets in 11 marine snow was about 8 times larger than in 11 ambient water. (c) Total volume of feral pellets in marine snow exceeded the total volume of fecal pellets by a factor of 1000 (note the logarithmic scale). (d) Contribution of fecal pellets of different volumes in 11 of 2 stages of marine snow: $(\Rightarrow)$ stringers $(<5 \mathrm{~cm})$ and $(\Rightarrow)$ clouds $(>1 \mathrm{~m})$

marine snow: $12 \%$ in July 1990 (Fig. 3a), $68 \%$ in June 1991 (Fig. 3b), and 12.5, 44 and $60 \%$, respectively, in July 1991 (Fig. 3c, d) depending on the type of marine snow. Short term changes were detectable in the size of fecal pellets between 3 and 12 July: fecal pellets were generally smaller, more homogeneous in size and more abundant on 12 July than on 3 and 4 July, when they displayed a broad size spectrum with fecal pellets reaching a volume of up to $4.1 \times 10^{6} \mathrm{um}^{3}$ (Fig. 3c, d). In July 1990, we also found high numbers of equally shaped large fecal pellets with a maximum volume of $3.9 \times 10^{6} \mu \mathrm{m}^{3}$ (Fig. 3a, Table 2) which were present only when polychaete larvae were also abundant in marine snow. Direct observations revealed that polychaete larvae egested those long cords of up to $1 \mathrm{~mm}$ in length (Table 2) (Bochdansky \& Herndl 1992). Four different types of fecal pellets could be distinguished: small translucent cylindrically shaped fecal pellets mainly derived from cladocerans and small copepods $1<200$ $\mu \mathrm{m})$, larger densely packed from copepods (>200 $\mu \mathrm{m})$,

Table 2. Characteristics of the 4 main types of fecal pellets commonly found during the investigation period. SD: 1 standard deviation in $\%: n$ : no. of replicates: 'Membrane' stands for a refractory structure enclosing its content

\begin{tabular}{|c|c|c|c|c|c|c|}
\hline Origin & Length $(1 \mathrm{~mm})$ & Width (um) & Shape & Color & Membrane & Content \\
\hline $\begin{array}{l}\text { Cladocerans \& } \\
\text { Small copepods }\end{array}$ & $\begin{array}{c}86.2 \\
(\mathrm{SD} 49 \%, \mathrm{n}=18)\end{array}$ & $\begin{array}{c}15.1 \\
(\mathrm{SD} 49 \%, \mathrm{n}=18)\end{array}$ & Cylindrical & Light & $\begin{array}{l}\text { Hardly } \\
\text { visible }\end{array}$ & $\begin{array}{l}\text { Heterogeneous, } \\
\text { translucent }\end{array}$ \\
\hline Larger copepods & $\begin{array}{c}201.6 \\
(\mathrm{SD} 27 \%, \mathrm{n}=26)\end{array}$ & $\begin{array}{c}42.8 \\
(\mathrm{SD} 28 \%, \mathrm{n}=26)\end{array}$ & Cylindrical & Brown & Thick & $\begin{array}{l}\text { Homogeneous, } \\
\text { droplets }\end{array}$ \\
\hline $\begin{array}{l}\text { Unknown (found } \\
\text { only in Sep) }\end{array}$ & $\begin{array}{c}29.6 \\
(\mathrm{SD} 21 \%, n=11)\end{array}$ & $\begin{array}{c}16.6 \\
(\mathrm{SD} 37 \%, \mathrm{n}=11)\end{array}$ & Oval & Black & Thick & Densely packed \\
\hline Polychaete larvae & ca 10 to ca 1000 & $\operatorname{ca} 42$ & Cords & Variable & Mucoid & $\begin{array}{l}\text { Heterogeneous, } \\
\text { loosely packed }\end{array}$ \\
\hline
\end{tabular}


black oval ones which were present only in September and long fecal pellets of polychaete larvae origin (Table 2)

The carbon content of fecal pellets with a mean volume of $1.63 \times 10^{5} \mu \mathrm{m}^{3}\left(\mathrm{SD}=5.2 \times 10^{4} \mu \mathrm{m}^{3}, \mathrm{n}=26\right)$ was $0.107 \mu \mathrm{g} \mathrm{C}$ (fecal pellet) ${ }^{-1}(\mathrm{SD}=0.034, \mathrm{n}=11$ ). The total organic carbon content (TOC) of marine snow ranged from 21 to $78 \mathrm{mg} \mathrm{Cl}{ }^{-1}$, clouds contained 65 to $318 \mathrm{mg} \mathrm{C}^{-1}$. The fecal pellet flux to the bottom estimated by sediment trap deployments ranged from $1.81 \times 10^{6}$ to $2.17 \times 10^{6}(\mathrm{n}=8)$ fecal pellets $\mathrm{m}^{-2} \mathrm{~d}^{-1}$ in September 1991. The number of fecal pellets produced by the mixed zooplankton sample in September 1991 increased as a linear function of time over $3 \mathrm{~h}$. On average the cladoceran-dominated mixed zooplankton produced 0.68 fecal pellets $h^{-1}$ ind. ${ }^{-1}(n=6, r=0.97$, $\mathrm{p}<0.001$ ) during daytime.

Within $1 \mathrm{~d}$, fecal pellets are colonized by ca 0.128 cells $\mu \mathrm{m}^{-2}$ (range: 0.015 to 0.185 cells $\mu \mathrm{m}^{-2}$ ). The equation for the linear regression is: no. of bacteria $\mu \mathrm{m}^{-2}=$ $0.018+0.11 \mathrm{~d}(\mathrm{r}=0.791, \mathrm{p}<0.001, \mathrm{n}=22)$. After $3 \mathrm{~d}$ fecal pellets with intact parts of their peritrophic membranes were scarce, after 5 d less than $5 \%$ of the fecal pellets were recognizable by their characteristically cylindrical shape. On Days 3 and 5 we found ca 2800 and 4600 bacteria (fecal pellet) ${ }^{-1}$, respectively.

After $6 \mathrm{~h}$, ca $50 \%$ of the fecal pellets treated with chitinase maintained their integrity; however, they easily fell apart after touching them with a dissecting needle. The fecal pellets kept in $0.2 \mu \mathrm{m}$ filtered seawater without chitinase added were still robust and could not be destroyed by only touching them. Furthermore, the water surrounding the chitinase-treated fecal pellets was turbid while it remained clear in the controls.

The number of fecal pellets adhering to glass surfaces at different flow velocities is shown in Fig. 4. More than $90 \%$ of the fecal pellets remained at the

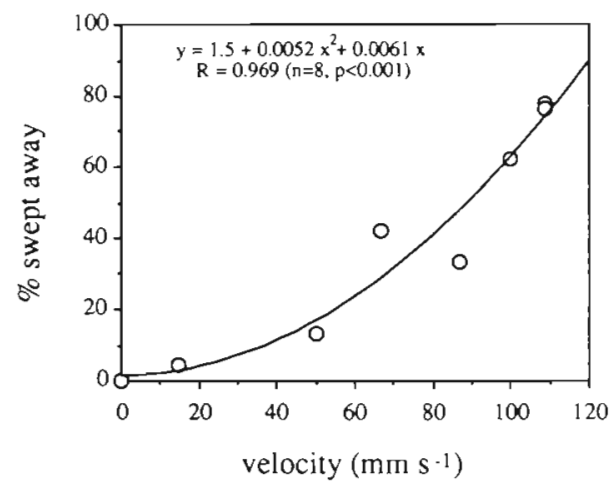

Fig. 4. Percentage of fecal pellets swept away at various current velocities in a capillary. The increasing number of fecal pellets swept away represents an increase of drag which is a function of the square of current velocity $\left(D=f\left(U^{2}\right)\right.$, Vogel 1981) glass surface at a flow velocity of the water of $20 \mathrm{~mm}$ $\mathrm{s}^{-1}$. The extrapolated speed where all the fecal pellets are swept away is around $120 \mathrm{~mm} \mathrm{~s}^{-1}$. The addition of a few drops of a strong detergent (Cephirol) into the seawater inflow caused the remaining fecal pellets to lose contact to the glass surface at $100 \mathrm{~mm} \mathrm{~s}^{-1}$ The glass beads were swept away at velocities of only $20 \mathrm{~mm} \mathrm{~s}^{-1}$

Discussion. During early summer the mesozooplankton in the Northern Adriatic Sea displayed the typical shift from an Acartia clausi dominated to a Penilia avirostris dominated community (Fonda Umani 1985). Therefore the cladocerans ( $P$. avirostris, Evadne sp. and Podon sp.) should be responsible for the major production of cylindrical fecal pellets $<10^{5} \mu^{3}$ during the summer. The fecal pellets in our production experiments using mixed zooplankton samples were similar in size and shape compared to the majority of fecal pellets found in marine snow. We did not detect oval fecal pellets in the size range from 20 to $300 \mu \mathrm{m}$ in length except in September 1991.

Fecal pellets present in marine snow reflect the recent feeding history of organisms in and outside marine snow. It is obvious that high numbers of intact fecal pellets in marine snow indicate strong grazing activity during the last few days. Our incubation experiments with fecal pellets in the laboratory and other studies in this context (Jacobsen \& Azam 1984, Novitsky 1990, Roy \& Poulet 1990) showed that fecal pellet membranes are rapidly colonized by bacteria and decomposed within a few days. Honjo \& Roman (1978) reported degradation of surface membranes within $3 \mathrm{~h}$ at $20^{\circ} \mathrm{C}$. In our experiments surface membranes remained intact for $1 \mathrm{~d}$ at $25^{\circ} \mathrm{C}$ in the major fraction $(>90 \%)$ of fecal pellets. Since only a few still intact fecal pellets $(<1 \%)$ were found on Day 5 in our incubation experiments, we might conclude that most of the fecal pellets lose their morphological integrity in less than 1 wk; they are, therefore, no longer recognizable especially in such a highly structured microenvironment like marine snow. This 'disappearance' of fecal pellets in marine snow is faster than the actual carbon remineralization (Jacobsen \& Azam 1984) and therefore much more material in marine snow is of fecal pellet origin than can actually be recognized by visual inspection. Bioturbation of organisms inhabiting marine snow (from protozoans to metazoans) (Lochte 1991, Turley 1991, Bochdansky \& Herndl 1992) could help to disintegrate fecal pellets.

Our samples exhibited high variations of fecal pellet abundance over time (Table 1). In late August enrichment factors (EF's) varied strongly with depth (Fig. 2). Low EF's of fecal pellets were detectable right below the pycnocline. This might have several reasons: (1) low abundance of zooplankton in this layer; (2) weak 
grazing activity in this depth layer; and (3) fecal pellets produced in upper layers were retained by the pycnocline. The fecal pellet production amounted to 16 ind. $^{-1}$ $\mathrm{d}^{-1}$ and is therefore similar to the values reported by Ayukai (1992; 9 to 13 fecal pellets ind.$^{-1} \mathrm{~d}^{-1}$ ) but much lower as compared to other studies (80 to 170 fecal pellets $d^{-1}$; Paffenhöfer \& Knowles 1979); our low rates, however, correspond to the low food concentrations in ambient water $\left(<0.2 \mu \mathrm{g}\right.$ chl a $\mathrm{l}^{-1}$; unpubl. data). Due to the comparatively high abundance of zooplankton in our experimental setup we might underestimate fecal pellet production because of shortage in food; the linear increase in fecal pellet abundance in the petridishes, however, indicates that scarcity of food or coprophagy did not bias our experiments significantly. Calculating the theoretical production derived from our experiments and the total mesozooplankton abundance in a $27 \mathrm{~m}$ water column with 14 ind. $1^{-1}$ we would expect a flux of ca $6 \times 10^{6}$ fecal pellets $\mathrm{m}^{-2} \mathrm{~d}^{-1}$. Our sediment trap deployment revealed a flux of $1.81 \times 10^{6}$ to $2.17 \times$ $10^{6}$ fecal pellets $\mathrm{m}^{-2} \mathrm{~d}^{-1}$. Although these values are in the same order of magnitude as the calculated rate they are about 3 times lower. This might indicate that fecal pellets are either retained at the pycnoclines or effectively scavenged by larger neutrally buoyant aggregates. For the Northern Adriatic Sea, reduced flux of particulate material through the stratified water column in the presence of large aggregates $(>1 \mathrm{~m}$ ) has been described for an annual cycle in a more detailed sediment trap study (Puskaric 1991).

The total volume of fecal pellets in marine snow is low compared to the overall marine snow volume (max. $=0.25 \%$, Fig. $3 \mathrm{~d}$ ) due to the high water content of the latter. In terms of carbon, however, fecal pellets contribute between 8.6 to $36.5 \%$ and in clouds from 5.2 to $25.7 \%$ to the TOC in marine snow (values were calculated on the basis of a conversion factor of $6.5 \times 10^{-7} \mu \mathrm{g}$ C $\mathrm{um}^{-3}$ of fresh fecal pellets). Fecal pellets may also contain living cells since it is known that many organisms such as bacteria (Gowing \& Silver 1983) and phytoplankton (Fowler \& Fisher 1983) survive gut passage. Thus the rapid sinking of fecal pellets can possibly seed deep marine waters and sediments with viable organisms (Fowler \& Fisher 1983). If fecal pellets become entrapped in marine snow these organisms would also become part of the microbial community in marine snow. The occurrence of larger fecal pellets $\left(>10^{6}, \mathrm{~m}^{3}\right)$ in marine snow compared to the ambient water (Fig. 3a, c) in July indicates the presence of polychaete larvae which have been observed to be able to produce long cords of up to $1 \mathrm{~mm}$ (Table 2). This specific larval community already described in Bochdansky \& Herndl (1992) feeds directly on marine snow. Therefore, these 'autochthonously' produced fecal pellets cannot be seen as a net flux of POM from the ambient water into marine snow but as a recycling of organic material produced on the basis of the marine snow-associated food web.

To some extent fecal pellets may contribute to particle aggregation as they could act as a nucleus for particle formation. At least cladoceran fecal pellet membranes contain adhesive substances as our measurements on the stickiness of fecal pellets indicate (Fig. 4). Since such high shear forces like those in our experiment cannot be expected in the natural environment, the probability of a permanent adhesion after the first contact is very high. We conclude therefore, that fecal pellets may enhance particle aggregation also via the input of adhesive agents.

Our findings that the addition of chitinase destroys the integrity of copepod fecal pellets show that chitin is probably the main structural compound of the membrane. This has been hypothesized by many authors since peritrophic membranes of carideans (Decapoda) (Forster 1953) and insects consist of chitin but it is in obvious contradiction to the experiments of Gauld (1957) and Honjo \& Roman (1978) where chitinase did not attack the surface membranes. The high abundance of fecal pellets in marine snow leads to an accumulation of chitin in marine snow. A higher chitinase activity in marine snow compared to the ambient water (Müller-Niklas \& Herndl unpubl.) can therefore be interpreted as a response of the microbiota to the high chitin input.

Aggregates in the Northern Adriatic Sea remain more or less neutrally buoyant over a long period of time displaying even bidirectional fluxes (Puskaric et al. 1992, Kaltenböck \& Herndl 1992). This prolonged residence time of these buoyant aggregates might provoke efficient scavenging of fecal pellets and is therefore an additional mechanism to the processes already described by Smetacek (1980), Krause (1981), Alldredge et al. (1987) and Small et al. (1987) for sustained residence of fecal material within the upper layers. We consequently may develop the following scenario for which fecal pellets serve as one example for particulate material: whenever large aggregates become condensed on pycnoclines, scavenging of fecal pellets dominates over the settlement of individual fecal pellets even in the shallow Northern Adriatic Sea $(<35 \mathrm{~m})$. Under such conditions decomposition of fecal pellets takes place in marine snow, fueling - together with other particles - the organic carbon pool of marine snow leading ultimately to a high degree of heterogeneity in the pelagic environment with patches of high organic matter concentrations surrounded by organic matter-depleted ambient waters.

Acknowledgements. We thank the staff of the Laboratorio di Biologia Marina at Aurisina (Trieste, Italy) and the staff of the Ruder Boskovic Institute (Rovinj, Croatia) for laboratory space 
and technical support. We thank Jörg Ott for comments and discussion during preparation of the manuscript. Pia Grubbauer, Andreas Heissenberger, Birgit Hoch and Doris Slezak contributed considerably to the experimental work during a marine ecology course in Rovinj in August/September 1991 This study was supported by the Austrian Science Foundation (FWF grant \# 7748-BIO to G.J.H.) and by the Alpen-Adria campaign on: 'Reasons and Consequences of the Occurrence of Gelatinous Aggregations in the Northern Adriatic Sea (Osservatorio dell'Alto Adriatico).

\section{LITERATURE CITED}

Alldredge, A. L., Gotschalk, C., MacKintyre, S. (1987). Evidence for sustained residence of microcrustacean fecal pellets in surface waters off southern California. Deep Sea Res. 34: 1641-1652

Alldredge, A. L., Silver, M. W (1988). Characteristics dynamics and significance of marine snow. Prog Oceanogr. 20: 41-82

Asper, V. L. (1987). Measuring the flux and sinking speed of marine snow aggregates. Deep Sea Res. 34:1-17

Ayukai, T (1992). Production and downward flux of zooplankton fecal pellets in the anticyclonic gyre of Shikoku, Japan Oceanol. Acta 15: 163-172

Bathmann, U. V., Noji, T T., Voss, M., Peinert, R. (1987) Copepod fecal pellets: abundance, sedimentation and content at a permanent station in the Norwegian Sea in May/ June 1986. Mar. Ecol. Prog Ser. 38: 45-51

Bochdansky, A. B., Herndl, G. J. (1992). Ecology of amorphous aggregations (marine snow) in the Northern Adnatic Sea III. Zooplankton and interactions with marine snow. Mar Ecol. Prog. Ser 87 135-146

Emerson, C. W., Roff, J. C. (1987). Implications of fecal pellet size and zooplankton behaviour to estimates of pelagic-benthic carbon flux. Mar Ecol. Prog. Ser 35: 251-257

Fonda Umani, S. (1985). Quantitative contribution of Acartia clausi Giesbrecht and Penilia avirostris Dana to zooplankton biomass in the Gulf of Triest. Atti dell secondo Congresso Nationale della Società Italiana di Ecologia 1984 S.I.T.E. Atti 5: 235-237

Forster, G. R. (1953). Peritrophic membranes in the Caridea (Crustacea Decapoda). J. mar biol. Ass. U.K. 32: 315-318

Fowler, S. W., Fisher, N. S. (1983). Viability of marine phytoplankton in zooplankton fecal pellets. Deep Sea Res. 30 963-969

Gauld, D. T. (1957). A peritrophic membrane in calanoid copepods. Nature 179: $325-326$

Gowing, M. M., Silver, M. W. (1983). Origins and microenvironments of bacteria mediating fecal pellet decomposition in the sea. Mar. Biol. 73: 7-16

Herndl, G. J., Karner, M., Peduzzi, P. (in press). Floating mucilage in the Northern Adriatic Sea: the potential of a microbial ecological approach to solve the 'mystery' Sci. Total Environ.

Honjo, S., Roman, M. R. (1978). Marine copepod fecal pellets production, preservation and sedimentation. J. mar. Res. 36: $45-57$

Jacobsen, T. R., Azam, F. (1984). Role of bacteria in copepod

This note was submitted to the editor fecal pellet decomposition: colonization, growth rates and mineralization. Bull. mar Sci. 35: 495-502

Kaltenböck, E., Herndl, G. J. (1992). Ecology of amorphous aggregations (marine snow) in the Northern Adriatic Sea. IV Dissolved nutrients and the autotrophic component associated with marine snow. Mar. Ecol. Prog. Ser 87-147-159

Krause, M. (1981). Vertical distribution of fecal pellets during FLEX 76. Helgoländer Meeresunters. 34: 313-327

Lampitt, R. S., Noji, T., von Bodungen, B. (1990). What happens to zooplankton faecal pellets? Implications for material flux. Mar Biol. 104. 15-23

Lochte, K. (1991). Protozoa as makers and breakers of marine aggregates. In: Reid, P. C., Turley, C. M., Burkill, P. H. (eds.) Protozoa and their role in marine processes. NATO ASI series vol. G 25. Springer Verlag, Berlin, p. 327-346

Lochte, K., Turley, C. M. (1988). Bacteria and cyanobacteria associated with phytodetritus in the deep sea. Nature 333: $67-69$

Novitsky, J. A. (1990). Evidence for sedimenting particles as the origin of the microbial community in a coastal marine sediment. Mar Ecol. Prog. Ser. 60: 161-167

Paffenhöfer, G. A., Knowles, S. C. (1979). Ecological implications of fecal pellet size, production and consumption by copepods. J. mar. Res. 37: 35-49

pilskaln, C. H. Honjo, S. (1987). The fecal pellet fraction of biogeochemical particle flux to the deep sea. Global Biogeochem. Cycles 1. 31-48

Puskaric, S. (1991). Annual cycle of particle flux in the Northern Adriatic Sea. Ph.D. thesis, Univ. of Zagreb

Puskaric, S., Fowler, S. W., Miquel, J. C. (1992). Temporal changes in particulate flux in the Northern Adriatic Sea. Estuar, coast. Shelf Sci. 35: 267-278

Roy, S., Poulet, S. A. (1990). Laboratory study of the chemical composition of aging copepod fecal material. J. exp. mar. Biol. Ecol. 135: 3-18

Small, L. F., Fowler, S. W., Ünlü, Y. (1979). Sinking rates of natural copepod fecal pellets. Mar. Biol. 51: 233-241

Small, L. F., Knauer, G. A., Tuel, M. D. (1987). The role of sinking fecal pellets in stratified euphotic zones. Deep Sea Res. 34: 1705-1712

Smetacek, V. S. (1980). Zooplankton standing stock, copepod faecal pellets and particulate detritus in Kiel Bight. Estuar. coast. mar Sci. 11: 411-418

Smetacek, V (1985). Role of sinking in diatom life-history cycles: ecological, evolutionary and geological significance. Mar Biol. 84: 239-251

Stachowitsch, M. Fanuko, N., Richter, M. (1990). Mucus aggregates in the Adriatic Sea: an overview of stages and occurrences. P.S.Z.N. I: Mar. Ecol. 11: 327-350

Suess, E. (1980). Particulate organic carbon flux in the oceans. surface productivity and oxygen utilization. Nature 288: 260-263

Turley, C. M. (1991). Protozoa associated with marine 'snow' and 'fluff' - session summary. In: Reid, P. C., Turley, C. M., Burkill, P. H. (eds.) Protozoa and their role in marine processes. NATO ASI series vol. G 25. Springer Verlag, Berlin, p. 309-326

Urrère, M. A., Knauer, G. A. (1981). Zooplankton fecal pellet fluxes and vertical transport of particulate organic material in the pelagic environment. J. Plankton Res. 3: 369-387

Vogel, S. (1981). Life in moving fluids: the physical biology of flow. Willard Grant Press, Boston

Manuscript first received: April 3, 1992

Revised version accepted: October 15, 1992 